\title{
VACCINE NATIONALISM AND EQUITABLE ACCESS TO COVID-19 PHARMACEUTICALS: TRIPS AGREEMENT UNDER TRIAL (AGAIN).
}

\begin{abstract}
The global scramble for COVID-19 vaccine and other related pharmaceutical products have once again exposed the limitations of the Agreement on TradeRelated Aspects of Intellectual Property Rights (TRIPS Agreement). High-Income countries are claiming a lion's share of the first available batches of the COVID-19 vaccine in total disregard of the consequences such approach would have on the Low-Income countries who lack both the manufacturing wherewithal and the financial resources to purchase the vaccine and other products needed to combat the pandemic.
\end{abstract}

This paper reviews the existing TRIPS Flexibilities and analyses their limitations with respect to equitable access of pharmaceutical products in times of health emergencies. The paper then considers the unique challenges that have been brought to the fore by the COVID-19 pandemic. Finally, the paper analytically explores some options that have been proposed so far that the WTO or governments can take in the immediate to near term to facilitate equitable access to COVID-19 pharmaceutical products and technologies.

The paper finds that there is still need for a comprehensive reform of TRIPS Agreement to streamline the voluntary licensing system which is an important tool for low-income countries' access to affordable pharmaceuticals. However, for purposes of dealing with COVID-19, WTO members should consider establishing pooled licensing facilities and procurement strategies via already existing political, economic, or regional trade groupings.

KEYWORDS: International Trade Law, TRIPS Agreement, TRIPS Flexibilities, TRIPS COVID-19 Vaccines, Vaccine nationalism, Mandatory Patent Pools, Regional Pharmaceutical Supply Centres, COVID-19 Technology Access Pool and the voluntary Medicines Patent Pool.

\section{INTRODUCTION}

The global scramble for COVID-19 vaccine and other related pharmaceutical products have once again exposed the limitations of the Agreement on TradeRelated Aspects of Intellectual Property Rights ('TRIPS'). High-Income countries have so far claimed a lion's share of the available COVID-19 vaccine in total disregard of the consequences such approach would have on the low-income 
countries who lack both the manufacturing wherewithal and the financial resources to purchase the vaccine and other products needed to combat the pandemic.

COVID-19 pandemic comes on the heels of the ratification of the formal amendment to TRIPS Agreement on 23 January 2017 after years of negotiations. COVID-19 is, therefore, the first global public health emergency facing WTO members after the ratification of the formal amendment. The amendment incorporated different measures that have been put in place to reduce the adverse impact of the agreement on developing countries to enable them deal with health emergences (collectively referred to as "TRIPS Flexibilities"). Specifically, the amendment seeks to facilitate access to cheap pharmaceuticals in the form of 'generic versions' of patented products through the voluntary licensing facility.

However, despite this amendment being currently in place and part of TRIPS, the reality on the ground, with regard to dealing with COVID-19 pandemic, shows a contrary outlook. Developing countries are having difficulties in accessing the vaccine due to 'vaccine nationalism', perpetrated by countries, which have the resources and control over production of the vaccine. It is clear that the formal amendment and the rest of the exemptions that are provided for under TRIPS for purposes of dealing with public health emergencies like COVID-19, have made little, if any difference, in facilitating equitable access to COVID-19 pharmaceuticals by low-income countries.

This paper finds that despite several measures that are in place for purposes of facilitating equitable access to pharmaceutical products needed to deal with health emergences in low-income countries, there are still issues regarding the effectiveness of the existing system. The waiver that was introduced through the 2003 Decision and later incorporated in the formal amendment has not cut deep enough. The procedural framework for voluntary licencing system is considered to be cumbersome and therefore less appealing to the intended end users of the system. It is observed that the solutions required to deal with COVID-19, involve wide-ranging IP issues beyond patents, which means that there is need for a comprehensive review of the current IP regulatory landscape. However, historically and generally, reviews of WTO instruments take time and time is the luxury the world do not have in so far as combating COVID-19 is concerned.

As such there is need to find alternative stopgap solutions for purposes of facilitating equitable access to COVID-19 pharmaceuticals. One of such solutions is the proposal by India and South Africa concerning a temporary waiver of the provisions of TRIPS that would ordinarily stand in the way of equitable access to COVID-19 pharmaceuticals. Although this proposal has received mixed reactions within the WTO family, this paper finds it to be a sensible and reasonable solution. However, in light of the said mixed reaction, it is doubtful that the proposal will see the light of day. Another solution is the proposal by Abbott and Reichman on the establishment of Mandatory Patent Pools (Licensing Facilities) and Regional Pharmaceutical 
Supply Centres (RPSCs) to facilitate pooled licencing and procurement of COVID-19 pharmaceuticals. While this proposal is considered to be a viable and reasonable short to medium term solution, implementation of such arrangements may require a bit more time. As such, this paper proposes that WTO members should use already existing political and economic groupings that they belong to, as vehicles for such arrangements.

This research is non-empirical, desk-based research. It is, therefore, based on literature review of existing body of work that is relevant to the topic under discussion. Mindful of the epistemological challenges that are always associated with desk-based research, part of the methodology of this work is to seek support from related empirical studies based on different philosophical underpinnings but that confirm the working hypothesis of this research. This method, which is modelled on the "two source rule" of classic journalism ${ }^{1}$, requires that generalised claims should be anchored on more than one body of independent evidence, and where there are divergent results from credible sources, the disparity should be noted and acknowledged. ${ }^{2}$ In using this method, I have remained cognizant of the dangers of selecting from the evidence only that, which supports the hypothesis and rejecting that which is obstructive to the same. ${ }^{3}$

This paper will proceed as follows. Section 2 discusses the phenomenon of vaccine nationalism, which has emerged in the wake of COVID-19 pandemic and its impact on equitable access to Covid -19 pharmaceuticals by low-income countries. In section 3 the paper reviews the TRIPS Agreement and its role of protecting intellectual property rights. Section 4 engages in a review of different TRIPS Flexibilities and their historical limitations in facilitating equitable access to pharmaceutical products during public health emergencies. Section 5 looks at a number of efforts that have been made to reform the TRIPS agreement in response to identified problems faced by low-income countries in accessing pharmaceuticals needed to deal with public health emergences. Section 6 focuses on the formal amendment to the TRIPS agreement, which was put together in order to implement Article 6 of the Declaration on TRIPS Agreement and Public Health. Section 7 looks at the limitations of TRIPS Agreement while in section 8 the paper considers the unique challenges brought about by Covid-19 pandemic, which does not only involve patents but also issues relating to industrial designs, copyrights and trade secrets. Finally, section 9 critically explores possible solutions to the supply chain bottlenecks created by TRIPS Agreement with respect to equitable access to COVID-19 pharmaceuticals and technologies.

\section{VACCINE NATIONALISM AND EQUITABLE ACCESS TO COVID-19 VACCINE.}

\footnotetext{
${ }^{1}$ This rule says that every rumour or tip must be double checked before it is published.

2 Robert D Putnam, Bowling Alone (Simon \& Schuster Paperbacks, New York 2000).

${ }^{3} \mathrm{~K}$. Popper, The Poverty of Historicism. (Routledge, London 2002) 124
} 
As COVID-19 has been a global pandemic in the true sense of that expression, dealing with the pandemic requires a global solution. This means that in order for any medical intervention to be effective, such intervention needs to be global in its reach and administration. There is now a consensus that, in so far as COVID-19 is concerned, no country will be safe until ALL countries are safe. As such, the efficacy of any COVID-19 intervention including vaccination, will depend on how quickly they can be accessed by all countries. However, this ideal has been threatened by the scramble for the vaccine by developed countries who are desperate to reverse the current economic downward spiral before their economies crashes down. In recognition of this worrying trend the WHO Director General, Tedros Adhanom, warned that such 'vaccine nationalism would condemn many countries to prolonged suffering, which means a slower economic recovery worldwide'4.

Vaccine nationalism is a phenomenon where countries in which vaccines are manufactured, mostly rich countries, restrict access to the vaccine by other countries. Such countries usually claim a lion's share of the available vaccine in the initial stages of availability of the same to the exclusion of other countries. This conduct unduly increases demand of the product, such that even the little that may be available for deployment in other countries becomes an expensive product not affordable by most poor economies. This dynamic has fully played out with respect to COVID-19 vaccine. High income economies like United Kingdom and United States pre-ordered the bulk of the vaccines at development stage through deals known as advance market commitments (AMCs) or Advance Purchase Agreements (APAs). AMCs or APAs are legally binding contracts whereby one party, such as a government, commits to purchasing from a vaccine manufacturer a specific number or percentage of doses of a potential vaccine at a negotiated price if it is developed, licensed, and proceeds to manufacture. ${ }^{5}$ A recent research conducted by the Global Health Innovation Centre at Duke University indicated that COVID-19 vaccine orders placed by high-income countries, accounted for more than half of all the AMCs. ${ }^{6}$ It is actually feared that less-well-off countries may have to wait years to vaccinate their people. $^{7}$

While AMCs and APAs are regarded as important as they provide funds in advance to manufacturers for Research and Development ( $\&$ \&), such bilateral legal

\footnotetext{
${ }^{4}$ Tedros Adhanom, 'Why vaccine nationalism harms efforts to halt the pandemic,' The Economist, $08^{\text {th }}$ September 2020.

${ }^{5}$ Alexandra L Phelan, Mark Eccleston-Turner, Michelle Rourke Allan Maleche, Chenguang Wang, 'Legal agreements: barriers and enablers to global equitable COVID-19 vaccine access' (2020) Vol. 396, ISSUE 10254, The Lancet, pp 800-802. Available online at https://doi.org/10.1016/S0140-6736(20)31873-0

${ }^{6}$ Duke Global Health Institute, 'Will Low-Income Countries Be Left Behind When COVID-19 Vaccines Arrive?' 09 November 2020. <https://globalhealth.duke.edu/news/will-low-income-countries-be-left-behind-when-covid19-vaccines-arrive> accessed on 22 February 2021

${ }^{7}$ The Economist, 'Rich countries grab half of projected covid-19 vaccine supply', 12 ${ }^{\text {th }}$ November 2020.
} 
agreements are likely to contribute to inequities and potentially extend the pandemic's time frame ${ }^{8}$.

One solution to this problem is to take a multilateral approach to COVID-19 vaccine procurement, deployment and distribution. An example of such vaccine multilateralism is the COVAX Global Vaccines Facility established under the auspices of the World Health Organisation and two non-profit groups, GAVI and the Coalition for Epidemic Preparedness Innovations. The stated objective of COVAX is to facilitate some level of coordination from vaccine production to distribution in order to ensure access to a wide portfolio of COVID-19 vaccines being developed and tested ${ }^{9}$. The COVAX alliance modus operandi include jointly financing COVID-19 research and committing to purchase billions of vaccines from many companies thereby providing a significant share of the money up front to enable the manufacturers to invest right away in production ${ }^{10}$. This would help to scale up the manufacturing capacity to ensure that all countries in the consortium have access to the vaccine at the same time.

However, the COVAX facility is not a silver bullet to equitable accessibility of COVID19 as its stated aspiration is to "to vaccinate the most vulnerable $20 \%$ of the population of every country that participates." 11 This means that low-income countries will still have to source out a significant amount of the vaccine needed to inoculate the majority of their populations using their own resources. As such, the need for access to cheaper versions of the vaccines is still relevant and so is the impact of TRIPS on the accessibility of the vaccine.

\section{TRIPS AGREEMENT AND PROTECTION OF INTELLECTUAL PROPERTY RIGHTS.}

The stated objective of TRIPS is to facilitate international trade through the promotion of effective and adequate protections of intellectual property rights (IP Rights) and to ensure that enforcement of IP rights do not restrict legitimate trade. ${ }^{12}$ In essence, WTO members are obligated under the provisions of TRIPS to ensure that IP rights are not infringed upon within their jurisdiction and if they are, they should have measures in place for enforcement of any registered IP rights. ${ }^{13}$ WTO members are obligated to make patents available, for any inventions, whether products or processes, in all fields of technology, providing that they are new, involve

\footnotetext{
${ }^{8}$ Phelan et al, (n.2)

${ }^{9}$ Seth Berkley, 'COVAX Explained', 3 September 2020. <https://www.gavi.org/vaccineswork/covax-explained.> accessed on 21 February 2021

${ }^{10}$ Ibid.

${ }^{11}$ World Health Organisation, 'More than 150 countries engaged in COVID-19 vaccine global access facility' 15 July 2020. <https://www.who.int/news/item/15-07-2020-more-than-150-countries-engaged-in-covid-19vaccine-global-access-facility $>$. accessed on 22 February 2021.

12 Preamble to TRIPS Agreement.

${ }^{13}$ Article 27, TRIPS Agreement.
} 
an inventive step and are capable of industrial application. ${ }^{14}$ Exclusive Rights of patent owners include rights to prevent third parties from using, offering for sale, sale, selling or importing for these purposes any potential product without consent of the patent owners. ${ }^{15}$ This entails that any patented product cannot be manufactured or marketed in any jurisdiction where the patents apply without express consent of the patent owner.

With respect to medicines, patented medicinal products will usually be expensive due to market forces of demand and supply as they will always be high demand and low supply. Under the relevant provisions of TRIPS, such products cannot be manufactured, marketed, or sold in any country without permission of the IP rights owner for the same. This poses a potentially significant obstacle to importation of pharmaceutical products mainly by developing countries.

The solution to this problem is to facilitate the development of 'generic' or 'off-patent' medicines. Such generic versions of patented products are manufactured by third party companies that have been granted a licence to do so by the patent owners. Generic medicines are usually produced in large quantities and therefore, they are cheaper than the original version of the medicine ${ }^{16}$. TRIPS provides for a framework on production of generic pharmaceuticals under what are called "TRIPS Flexibilities".

\section{TRIPS FLEXIBILITIES}

Developing countries are usually hit hard by the restrictions under TRIPS and this disadvantaged position has been long known by WTO members. As such, a number of measures have been put in place to reduce the adverse impact of the agreement on developing countries. These measures are collectively known as 'TRIPS Flexibilities' as they, effectively, provide for a relaxation of the strict TRIPS provisions.

Firstly, developing countries and least developed countries were granted longer transition period to implement TRIPS. While all members were given a period of one year until 1 January 2000, developing countries were given until 1 January 2005, while least developed countries were given up to 1 January 2006 to implement the provisions of TRIPS. This period was extended firstly to 1 July 2021 or until the date on which the member involved graduate from the Least Developed Country (LCD) status whichever, is the earlier. The period has now been further extended to 1 July 2034 or until the date on which the member ceases to be a LDCs, whichever date is earlier ${ }^{17}$.

\footnotetext{
${ }^{14} \mathrm{Ibid}$.

${ }^{15}$ Article 28 of TRIPS Agreement

${ }^{16}$ See, Fredrick Abbot, 'The Doha Declaration on the TRIPS Agreement and Public Health: Lighting a Dark

Corner at the WTO', 2002 (5) Journal of international Economic Law, 469 at 472.

${ }^{17}$ Decision of the Council for TRIPS of 29 June 2021.
} 
The net effect of these extensions of implementation period with respect to pharmaceutical products, is that LDCs can manufacture or access generic medicines without falling foul of the provisions of TRIPS until the extension has expired or the countries are out of the LDC category. Thus, in its decision of 08 July 2002, the WTO General Council approved a special waiver exempting LDCs from their obligation under Article 70.9 of TRIPS to provide exclusive marketing rights for any new drugs in the period when they do not provide patent protection. ${ }^{18}$

Apart from the longer implementation periods, TRIPS contains a number of provisions, the effect of which is to relax the stringent obligations under TRIPS. Firstly, Article 7 of TRIPS integrates a balance of the rights of patent owners and the end users of technological innovations and specifically provides that protection and enforcement of IP rights should be undertaken in a manner conducive to social and economic welfare. Article 8 of TRIPS allows WTO members to adopt measures necessary to protect public health and nutrition and to promote the public interest in sectors of vital importance to their social-economic and technological development. While it could be argued that Article 8 gives developing countries some level of latitude to derogate from the strict restrictions under TRIPS, it is observed that the flexibility intended by Article 8 is limited by the requirement that any such measure should be consistent with the provisions of TRIPS. ${ }^{19}$

Another relevant provision of TRIPS is Article 30, which allows WTO members to provide limited exceptions to the exclusive rights of patent owners as long as such exceptions do not unreasonably conflict with the normal exploitation of the patent and do not prejudice, the legitimate interest of the patent owner.

The interplay of Articles 7, 8 and 30 was considered in the case of CanadaPharmaceutical Patents (2000)20 where the European Communities challenged provisions of Canada's patent law that allowed producers of generic medicines before the expiry of the patent term, to stockpile generic products and use patented products to prepare their submissions for marketing authorisation of a generic version. In its submissions, Canada sought to rely on the exception in Article 30 to justify its measures and argued that the objectives and principles of Articles 7 and 8 of the TRIPS Agreement should inform the interpretation of Article 30. The WTO Panel held that:

"Article 30's very existence amounts to a recognition that the definition of patent rights contained in Article 28 would need certain adjustments. On the other hand, the three limiting conditions attached to Article 30 testify strongly that the negotiators of the Agreement did not intend Article 30 to bring about what would be equivalent to a

\footnotetext{
${ }^{18}$ WTO, 'Least-Developed Country Members - Obligations Under Article 70.9 of the TRIPS Agreement with Respect to Pharmaceutical Products' Decision of 8 July 2002.

$<$ https://www.wto.org/english/tratop e/trips e/art70 9 e.htm> accessed on 23 February 2021

${ }^{19}$ Peter Van den Bossche, The Law and Policy of the World Trade Organization: Text, Cases and Materials (4th eds. CUP: 2017) p.996

${ }^{20}$ Canada - Patent Protection of Pharmaceutical Products, WT/DS114/R, 17 March 2000
} 
renegotiation of the basic balance of the Agreement. Obviously, the exact scope of Article 30's authority will depend on the specific meaning given to its limiting conditions. The words of those conditions must be examined with particular care on this point. Both the goals and the limitations stated in Articles 7 and 8.1 must obviously be borne in mind when doing so as well as those of other provisions of the TRIPS Agreement which indicate its object and purposes." 21

Perhaps, the most important facility that is available to the developing countries is compulsory licensing provided for under Article 31 of TRIPS. This provision allows for an exception to the exclusive rights over patented products by allowing WTO members to come up with laws that authorise 'other use' of a patented product without the authorisation of the patent owner. ${ }^{22}$ The authorised 'other use' can be by the government or a third party authorised by the government. Through the flexibility under Article 31, a WTO member is allowed to grant a compulsory licence to a pharmaceutical company within its jurisdiction either to manufacture or import a patented pharmaceutical product. In order to grant the compulsory license, the member will have to comply with the conditions set out in paragraphs (a) to (I) of Article 31. The most relevant conditions are that (i) the proposed user, before using the subject matter of the patent, should make efforts to obtain authorisation from the right holder on reasonable commercial terms and conditions, ${ }^{23}$ (ii) the use must be authorised predominately for the supply of the domestic market of the member authorising such use, ${ }^{24}$ and (iii) that the right holder be paid adequate remuneration in the circumstances of each case ${ }^{25}$.

The requirement of 'making an effort to obtain authorisation from the patent owner' can be waived in the case of a national emergency or other circumstances of extreme urgency or in cases of public non-commercial use. ${ }^{26}$ The use of compulsory licences in cases of 'national emergency' recognises the need to ensure affordable access to essential medicines to deal with public health crises. Compulsory licences may be used to authorise producers of generic medicines to copy a patented drug, without the consent of the right holder. ${ }^{27}$

However, the provision of Article 31(f), which restricts the use of any pharmaceutical products produced under a compulsory licence to be predominately for the supply of the domestic market, is problematic to most developing countries that have no sufficient capacity to manufacture the requisite pharmaceuticals under compulsory licence. In so far as these countries cannot manufacture generic pharmaceutical products within their jurisdiction, the compulsory licencing facility is rendered

\footnotetext{
${ }^{21}$ Ibid. Para. 7.26.

${ }^{22}$ Article 31 of TRIPS Agreement

${ }^{23}$ Article 31 (b)

${ }^{24}$ Article 31 (f)

${ }^{25}$ Article 31 (h)

${ }^{26}$ Article 31 (b)

${ }^{27}$ Peter Van den Bossche, (n.16)
} 
nugatory. Further, on account of the restriction under Article 31(f), countries that have no capacity to manufacture the products can also not import any pharmaceutical products produced under the compulsory licence. This entails that only a small portion of pharmaceutical products manufactured under compulsory licences around the world can be legitimately exported to countries in need and lacking manufacturing capacity. ${ }^{28}$ Since this conundrum was discovered, WTO members have been engaged in a long-winded process of reforming TRIPS to ensure that the spirit of TRIPS flexibilities is reflected in practice.

\section{THE ROAD TO REFORMING TRIPS AGREEMENT}

As a confirmation of the recognition of the adverse impact of TRIPS on developing countries' access to affordable pharmaceutical products, WTO members issued the Declaration on the TRIPS Agreement and Public Health ("the Declaration") during the fourth WTO ministerial conference in Doha in 2001. First and foremost, the Declaration affirmed that TRIPS can and should be interpreted and implemented in a manner that is supportive of WTO members' right to protect public health and, in particular, to promote access to medicines for all. ${ }^{29}$ The Declaration also specifically recognised the right of members to grant compulsory licences and their freedom to determine the grounds upon which such licences are granted. ${ }^{30}$ Further, the Declaration granted each member a right to determine what constitutes a national emergency or other circumstances of extreme urgency. ${ }^{31}$

In keeping with the provisions of Article 66.1 of TRIPS, granting longer transmission periods, paragraph 7 of the Declaration provided that LCD countries would not be obliged, with respect to pharmaceutical products, to implement the obligations of the TRIPS Agreement regarding patents and the protection of undisclosed information or to enforce such IP rights until 1 January 2016. This was implemented by the TRIPS Council on 27 June 2002. On 6 November 2015, the TRIPS Council granted further extension for LCD's to implements their obligations with respect to pharmaceuticals to 1 January 2033.

Perhaps the most consequential provision of the Declaration is Article 6, where the members recognised the difficulty that LCD members with insufficient or no manufacturing capacities in the pharmaceutical sector face in making effective use of compulsory licencing due to the restriction provided for under Article 31 (f) of TRIPS. As such the members instructed the TRIPS Council to find an expeditious solution to this problem and to report to the General Council before the end of 2002.32 By way of

\footnotetext{
${ }^{28}$ Andrew D.Mitchell and Tania Voon. 'Patents and Public Health in the WTO, FTAs and Beyond: Tension and Conflict in International Law'(2009) 43 (3) Journal of World Trade 571-601 at p. 9.

${ }^{29}$ Para. 4 of the Declarations

${ }^{30}$ Para. $5 b$

${ }^{31}$ Para. 5c

32 Para. 6
} 
implementation of Article 6, the General Council made a decision in August 2003 ('the 2003 Decision') whereby WTO members agreed to waive the provisions of Article $31(\mathrm{f})$ so as to allow LCD members and other members lacking sufficient manufacturing capacity to import pharmaceutical products created under compulsory licence subject to certain conditions. Paragraph 1 of the decision defined a pharmaceutical product as 'any patented product or product manufactured through a patented process of the pharmaceutical sector, needed to address the public health problems as recognised in paragraph 1 of the Declaration'33. Under paragraph 3 , the decision provided a waiver of Article 31 (h) by exempting importing members from paying 'adequate remuneration' if the same has already been paid in the exporting member.

\section{FORMAL AMENDMENT OF TRIPS AGREEMENT}

In 2005, the WTO General Council agreed terms of an amendment of TRIPS as a formal implementation of Article 6 of the Declaration. This was done through the Protocol on amendment TRIPS Agreement. ${ }^{34}$ The protocol was mirrored on the 2003 Decision and sought to make the provisions of the Decision into permanent amendment of TRIPS. The amendment only entered into force on 23 January 2017 when it finally received acceptance of two-thirds of WTO members.

The amendment incorporated an additional Article 31 bis to TRIPS, which effectively allows pharmaceutical products made under compulsory licenses to be exported to countries lacking production capacity. ${ }^{35}$ The amendment also introduced a new annex to TRIPS, the provisions of which set out terms for using the compulsory licensing system, and cover such issues as definitions, notification, avoiding the pharmaceuticals being diverted to the wrong markets, developing regional systems to allow economies of scale, and annual reviews in the TRIPS Councilib. Finally, an appendix is added to the annex, which set out rules for assessing lack of manufacturing capability in the importing country.

Paragraph 5 of Article 31 bis, however, makes it clear that the provisions of the new article and the annex thereto are 'without prejudice to the rights, obligations and flexibilities' that Members have under TRIPS other than paragraphs ( $f$ ) and $(h)$ of Article 31. Which means the rest of the provisions of the original Article 31 are preserved apart from paragraphs $(f)$ and $(h)$.

\section{LIMITATIONS OF TRIPS AGREEMENT}

\subsection{Structural limitations of the voluntary licensing system}

\footnotetext{
${ }^{33}$ Para. 1 of the Decision

${ }^{34}$ WTO General Council, 'Amendment of Council of TRIPS Agreement' Decision of 6 December 2005, WT/L/641

${ }^{35}$ Article 31 bis (1)

${ }^{36}$ Annex to the TRIPS Agreement.
} 
While the amendment to TRIPS has solidified the waiver that was provided under the Declaration and the 2003 Decision, with respect to obligations under Article 31 of TRIPS, there are still some concerns with the waiver's practical utility.

While the amendment allows developing countries without manufacturing capacity to import generic pharmaceutical products, ${ }^{37}$ provisions of the Annex to TRIPS maintains the long-winded procedures that must be followed both by the exporting and importing countries. These include the requirement that the eligible importing Member(s) should make a notification to the TRIPS Council providing a whole range of information. ${ }^{38}$ The requirement of notifications and the nature of the information required as well as the obligation to adopt measures to avoid the 'diversion' of the products to other countries has been described as being 'more suitable for the export of weapons or dangerous materials than for products to address public health needs. ${ }^{39}$ The general criticism of voluntary licensing system is that its administrative prerequisites are cumbersome and has brought in more hurdles than the solution, which was sought by paragraph 6 of the Doha Declaration. Countries seeking to use the system to acquire generic medicines will have to go through many layers of procedure that will, in turn delay the manufacture and supply and increase the cost of the drugs ${ }^{40}$.

In so far as global production and commercialisation of any pharmaceutical product under the voluntary licencing as provided for under Article 31 bis of TRIPS remain under the control of the patent owner, any alternative supplier would be obligated to take several steps to manufacture and sell the product. ${ }^{41}$ Also issues around 'data exclusivity' may create an extra hurdle with respect to obtaining marketing approval of the product to be imported under a granted compulsory license..$^{42}$ As such, the common view is that the voluntary licencing system is designed to protect the patent owner rather than facilitating access to pharmaceutical products where needed and the system effectively 'legitimises the conduct of a patent owner who refuses to sell a product under his monopolistic control'43.

The problems of the voluntary licencing system in its current incarnation are borne out by the low usage of the system by WTO members. According to available records, since the introduction of the current system through the 2003 Decision, the

\footnotetext{
37 Para. 1 of article 31 bis

38 Para. 2 (a) of the Annex to the TRIPS Agreement

${ }^{39}$ Carlos M. Correa 'Will the Amendment to the TRIPS Agreement Enhance Access to Medicines?' The South

Centre Policy Brief No. 57, January 2019. P. 3. < https://www.southcentre.int/wp-

content/uploads/2019/01/PB57 Will-the-Amendment-to-the-TRIPS-Agreement-Enhance-Access-to-

Medicines EN-1.pdf> accessed 20 January 2021.

${ }^{40}$ S.K. Verma, 'TRIPS Agreement and Access to Medicines' (2006), p. 90-91

<http://www.kansaiu.ac.jp/ILS/publication/asset/nomos/29/nomos29-06.pdf> accessed 20 January 2021).

${ }^{41}$ Correa, (n.36) Such steps would include R \& D on the chemical compound and other technologies and seeking marketing approval, which in some cases may require demonstrating bioequivalence and bioavailability.

${ }^{42}$ Correa, (n.36) p.5.

43 Ibid.
} 
procedure has only been used once by Rwanda and Canada, for the exportation by a Canadian firm, Apotex, of a combination of anti-retroviral (Apo-TriAvir) to Rwanda. The active ingredients were protected by patents held by Boehringer Ingelheim (Canada) Ltd and GlaxoSmithKline Inc. in Canada, to whom Apotex was bound to request voluntary licenses as the first step to comply with the WTO Decision and the Canadian national law.

Several reasons have been cited for the lack of interest by members to use the system and these include "burdensomeness and complexity, economic and political pressures, reluctance in implementation and its failure to recognize the need for economies of scale for exporting countries. ${ }^{44}$

\subsection{TRIPS-Plus Provisions}

The growing use of TRIPS plus provisions, mainly by the United States, has resulted into a further dilution of TRIPS Flexibilities. TRIPS-Plus provisions are terms of bilateral or regional trade agreements that provide for more protection of IP rights than those provided under TRIPS. Most Free Trade Agreements championed by the US contain TRIPS-plus provisions. These provisions override the application of TRIPS flexibilities. Examples of TRIPS-plus provisions include provisions, which prevent national drug regulatory authorities from registering a generic version of a pharmaceutical product that is patented in the country, without the consent of the patent holder ${ }^{45}$ provisions prescribing data exclusivity periods, ${ }^{46}$ provisions extending patent terms where there is 'unreasonable' delay in registering the patent ${ }^{47}$ provisions requiring increased compensation for patent owners under voluntary licensing arrangements, ${ }^{48}$ and provisions prohibiting parallel importing. ${ }^{49}$

In an attempt to ameliorate the limitations created by its TRIP-Plus provisions, the US uses 'side letters' to provide a waiver for public health purposes. However, there are a number of criticisms against the effect of side letters.

The first criticism is that the interpretative value of the side letters is questionable because side letters do not form part of the actual text of FTAs, and it is considered that the provisions of side letters is likely to carry little legal weight in a dispute

\footnotetext{
${ }^{44}$ R. Thapa, 'Waiver Solution in Public Health and Pharmaceutical Domain Under TRIPS Agreement.' 2011 (16) Journal of Intellectual Property Rights', 470-6 at p. 474.

${ }^{45}$ Bryan Mercurio 'TRIPS-Plus Provisions in FTAs: Recent Trends' in Lorand Bartels and Federico Ortino, Regional Trade Agreements and the WTO Legal System, (Oxford Scholarship Online, 2012). at p.224.

46 Ibid, P. 227

${ }^{47} 8$ For example, Article 15(9)(6) of the CAFTA-DR states: "Each party, at the request of the patent owner, shall adjust the term of a patent to compensate for unreasonable delays that occur in granting the patent. For the purposes of this paragraph, an unreasonable delay shall at least include a delay in the issuance of the patent of more than five years from the date of filing of the application in the Party, or three years after a request for examination of the application has been made, whichever is later."

${ }^{48}$ An example of such FTAs is the US-Singapore FTA.

${ }^{49}$ Ibid.
} 
settlement proceeding ${ }^{50}$. Although the United States Trade Representative (USTR) has stated that the United States has no intention of using dispute settlement to challenge any country's actions that are in accordance with that solution, it is said that such statements cannot be relied upon and are not binding ${ }^{51}$.

Secondly, it is said that most side letters use ambiguous and vague language, which poses interpretative difficulties. For example, there is no consensus on what is a 'TRIPS/health solution'52. Also, some side letters state that the FTA does not affect 'necessary' measures to protect public health and it is observed that such a term is not used in the Doha Declaration and could be used restrictively to limit many health alternatives. Another specific example is the side letter with Oman, which seemingly restricts the ability of either party to issue compulsory licences to protect public health to situations of 'extreme' urgency. ${ }^{53}$ The interpretative difficulties associated with the text of side letters have been acknowledged by the World Bank, which stated as follows:

"Notwithstanding the potential flexibilities provided by these side letters, they raise several questions. How widely will the parties to the three agreements define the 'protection of public' health'- or, what definitions would an arbitration panel use? Uncertainty, in this respect may become itself a barrier to making use of the flexibilities and may open the door for restrictive interpretations by vested interest. Also, several of the other US FTAs do not contain comparable side letters, raising questions about conflicts between intellectual property obligations and public health objectives in at least some of the affected countries." 54

\subsection{US Unilateralism.}

Apart from insisting on inclusion of TRIPS-plus provisions in FTAs, the US has used another tool to effect more IP protection than provided for under TRIPS, mainly for purposes of protecting its pharmaceutical industry. ${ }^{55}$ Through the 'Special 301'

\footnotetext{
${ }^{50}$ Michael Handler and Bryan Mercurio, 'Intellectual Property', in Simon Lester and Bryan Mercurio (eds), Bilateral and Regional Trade Agreements (Cambridge University Press, 2009) pp. 308-341

51 Ibid.

52 Ibid

${ }^{53}$ US-Oman Side Letter on Public Health, 19 January 2006.

<http://www.sice.oas.org/Trade/USA OMN FTA e/asset upload file44 8808.pdf>last accessed on 19.07.2021.

${ }^{54}$ World Bank, Global Economic Prospects 2005: Trade Regionalism and Development (Washington, DC: World Bank, 2004), at p. 110, at http://go.worldbank.org/U051HQ8JZO.

${ }^{55}$ Mitchel et al (n. 25) p. 599
} 
Report issued annually by the Office of the US Trade Representative (USTR), ${ }^{56}$ the US places countries that are deemed to be in breach of IP rules on a Watch List or Priority Watch List. Countries that are on the Priority Watch List may be subject to an investigation and potentially trade sanctions. ${ }^{57}$ Further, inclusion on a Watch List or Priority Watch List may serve as an implicit threat of a potential dispute settlement challenge (in the WTO or even an FTA tribunal) or review of tariff preferences by the US government. ${ }^{58}$

Through this practice, the US imposes unilateral pressure on other countries to refrain from using TRIPS flexibilities to access cheaper medicines. ${ }^{59}$

\section{UNIQUE CHALLENGES BROUGHT ABOUT BY COVID-19 PANDEMIC.}

As stated above, COVID-19 has brought about far-reaching challenges to global health, which can only be tackled through global coordination. It is noted that the knowledge transfer required, in order to tackle COVID-19 involves various forms of intellectual property beyond patents, including industrial designs, copyrights and trade secrets ${ }^{60}$. Pharmaceutical companies and governments will need to share technologies to help detect, diagnose and trace people infected with the virus, protective equipment, smartphone technologies, software (e.g. needed for 3-D printing), artificial intelligence algorithms, data and databases. ${ }^{61}$

This entails that apart from dealing with the limitations of the TRIPS Flexibilities discussed above, tackling COVID-19 will require even more global ingenuity, coordination, and cooperation. There will be need for a comprehensive review of the current WTO legal framework that regulates and controls access to various lifesaving innovations to ensure that the relevant COVID-19 pharmaceuticals and technologies are accessed by all countries reasonably quickly and at an affordable price.

Some countries are already gearing up for engaging the compulsory licensing facility in order to procure the pharmaceuticals required to combat the pandemic. For example, Chile adopted a resolution declaring that the global coronavirus outbreak justifies the use of compulsory licensing to facilitate access to vaccines, drugs, diagnostics, devices, supplies, and other technologies useful for the surveillance,

\footnotetext{
56 The Special 301 report is meant to be used by USTR as a tool for monitoring and enforcing IP protection in accordance with multilateral and bilateral agreements, including the TRIPS Agreement and FTAs, although in practice it is used to effect greater IP protection.

${ }^{57}$ USTR, 2008 Special 301 Report (2008) 18.

58 Ibid.

${ }^{59}$ Mitchel et al (,25) p.599

${ }^{60}$ This has been noted in the proposal that has been jointly submitted by India and South Africa entitled to the TRIPS (Trade Related Aspects of Intellectual Property Rights) Council at the World Trade Organisation titled "Waiver from certain provisions of the TRIPS agreement for the prevention, containment and treatment of COVID19"

${ }^{61} \mathrm{lbid}$.
} 
prevention, detection, diagnosis and treatment of people infected by the COVID-19. ${ }^{62}$ As the world prepares to live with COVID-19, more countries will be resorting to use of compulsory licences in order to protect their populations.

\section{PROPOSED SOLUTIONS}

In light of the above discussion and analysis, it is clear that the current framework of TRIPS, is impeding equitable access to COVID-19 related pharmaceuticals. While the letter and the spirit of paragraph 6 of the Doha Declaration was clear and unambiguous, the implementation of the same through the 2003 Decision and later, the formal Amendment to TRIPS, failed to meet the desired outcome, which was to ensure that low-income countries are able to access cheap pharmaceutical products in times of public health emergencies. Scholars, civil society, and health practitioners have decried the ineffectiveness of the existing voluntary licencing rules right from the time they were promulgated through the 2003 Decision through to their incorporation in Article 31 bis of TRIPS.

Several reform proposals have been put forward, in an attempt to make the system more streamlined. In this section, we shall look at these reform proposals and also more recent proposals aimed at facilitating equitable access to COVID-19 pharmaceuticals. The need for immediate reform of TRIPS was acknowledged by the High-Level Panel on Access to Medicines established by the UN General Secretary in 2016, which recommended, among other things that:

"WTO Members should revise the paragraph 6 decision in order to find a solution that enables a swift and expedient export of pharmaceutical products produced under compulsory license. WTO Members should, as necessary, adopt a waiver and permanent revision of the TRIPS Agreement to enable this reform." ${ }^{23}$

There are a number of ways that have been proposed to properly implement paragraph 6 of the Doha Declaration beyond the waiver that was provided under the 2003 Decision.

\subsection{Further Amendment of TRIPS Agreement}

The first proposal which is more radical but considered to be more efficient with respect to equitable access to pharmaceutical products by low-income countries, is to remove paragraph (f) of article 31 of TRIPS that has created the problem addressed by the Doha Declaration. ${ }^{64}$ This would be an easy way of resolving the shortfalls of voluntary licensing system under TRIPS. However, such proposal is likely to meet the resistance of the high-income countries, who have always sought

\footnotetext{
${ }^{62}$ Resolution adopted by the Parliament of Chile on $17^{\text {th }}$ March 2020. <https://www.keionline.org/chileancovid-resolution> accessed on 30 January 2021.

${ }^{63}$ UN High Level Panel on Access to Medicines Report, 2016, p. 27, $<$ https://static1.squarespace.com/static/562094dee4b0d00c1a3ef761/t/57d9c6ebf5e231b2f02cd3d4/147389 0031320/UNSG+HLP+Report+FINAL+12+Sept+2016.pdf > accessed on 30 January 2021

${ }^{64}$ Correa, (n 36) p.7
} 
to protect the interests of pharmaceutical companies, which are mostly based in their jurisdictions. It should be remembered that it took 12 years for the recent Amendment of TRIPS to receive the acceptance of the required number of WTO members.

Secondly, it is proposed that WTO members may consider making it clear that 'the production for export of a patented product does not violate the patentee's exclusive rights as contemplated in article 28 of TRIPS. ${ }^{\prime} 5$ Such an authoritative interpretation would be necessary because article 28 in its current presentation provides for a blanket prohibition against 'making, using, offering for sale, selling, or importing'66 a patented product without the consent of the patent owner. As such this limits the utility of voluntary licensing system. Alternatively, individual WTO members may adopt this interpretation and although this may attract complaints under the WTO Dispute Settlement Understanding, such disputes may help to get the clarification from the WTO Dispute Settlement Body (DBS) over the wording of TRIPS. ${ }^{67}$

The third proposal is for WTO members to review the provisions of the new Article 31 bis of TRIPS and remove the conditions that has caused most problems for its effective use. Examples of such conditions include the limitation of a compulsory license to the quantity of products initially demanded by the importing country, and the need to request the patent owner for a voluntary license prior to applying and obtaining a compulsory license. ${ }^{68}$

However, in as much as these proposals may provide a solution to the current limitations, amending TRIPS again will not be easy and most importantly, may not be a realistic solution to the immediate need for equitable access to COVID-19 pharmaceuticals by low-income countries. As was the case with the recent amendment that incorporated Article 31 bis into TRIPS, it will take years before a consensus is reached. However, although WTO members may not go down this route for purposes of dealing with the COVID-19, the pandemic has further spotlighted the limitations of the compulsory licencing system that still exit even after the recent ratification of the amendment to TRIPS. Therefore, whether the proposed amendments are considered now or not, the case for further review of TRIPS remains strong and should remain on WTO's agenda for future consideration.

As an alternative to a further amendment of TRIPS, WTO members may seek to agree on another waiver, which is relatively easier to adopt than an amendment and may be enforced immediately. This is the proposal that South Africa and India have put forward as discussed below.

\subsection{The Proposal by South Africa and India}

\footnotetext{
${ }^{65} \mathrm{Ibid}$. This can be done by a three-fourths majority of the WTO members (under article IX(2) of the Agreement Establishing the WTO) adopting such an authoritative interpretation of TRIPS Agreement. ${ }^{66}$ Article 28 of TRIPS

67 Correa, (n 36) p.7

${ }^{68}$ Ibid at p. 7.
} 
South Africa and India have submitted a joint proposal to the TRIPS Council titled "Waiver from certain provisions of TRIPS for the prevention, containment and treatment of COVID-19"69, which aims at allowing all countries to be able to choose to not implement, apply or enforce patents and other intellectual property related to Covid-19 treatments, vaccines, diagnostics and other health technologies. ${ }^{70}$ The proposed waiver is broad and cover obligations relating to copyright and related rights, industrial designs, patents and the protection of undisclosed information. ${ }^{71}$ It is proposed that the waiver should last until widespread vaccination is in place globally and the majority of the world's population is immune ${ }^{72}$ but members would review the waiver annually until its termination.

The proponents of the waiver argue that the waiver would avoid barriers to the timely access to affordable medical products including vaccines and medicines or to scaling-up of research, development, manufacturing, and supply of essential medical products. ${ }^{73}$

While other countries are yet to state their position on the waiver, a number of developing and developed country members are opposing the waiver proposal on the ground that there is no indication that IP rights have been a genuine barrier to accessing COVID-19 related medicines and technologies. For instance, in its statement to the TRIPS Council, the United Kingdom stated that 'a waiver to the IP rights set out in TRIPS is an extreme measure to address an unproven problem' and that 'pursuing the proposed path would be counterproductive and would undermine a regime that offers solutions to the issues at hand'74. So basically, those who oppose the waiver believe that TRIPS has sufficient mechanisms to help developing countries access COVID-19 related medical products and technologies. It is observed that the evidence that is relied upon by the sponsors of the waiver points more to failures at the domestic level and less to limitations of TRIPS Agreement. ${ }^{75}$

Another key argument against the waiver is that it would disincentivise IPR owners to invest in innovation and thereby hinder the discovery and development of knowledge for new products or technologies. ${ }^{76}$ Mercurio $^{77}$ gives an example of the synthetic mRNA technology, which has played a vital role in the development of Pfizer and Moderna Covid-19 vaccine and notes that this technology has been at $R \& D$ stage

\footnotetext{
${ }^{69}$ World Trade Organisation, 'Waiver from certain provisions of the TRIPS agreement for the prevention, containment and treatment of COVID-19', IP/C/W/669, 02 October 2020.

$<$ https://docs.wto.org/dol2fe/Pages/SS/directdoc.aspx?filename=q:/IP/C/W669.pdf\&Open=True > accessed on 30 January 2021

70 Ibid. paras 3 and 5.

71 Ibid. para. 12.

72 Ibid. para. 13

${ }^{73}$ Ibid.

${ }^{74}$ UK Statement to the Council for TRIPS dated dated 16 October 2020.

<https://www.gov.uk/government/news/uk-statement-to-the-trips-council-item-15> accessed on 30 January 2021.

${ }^{75}$ Bryan Mercurio, WTO Waiver from Intellectual Property Protection for Covid19 Vaccines and Treatments: A

Critical Review, Virginia Journal of International Law Online p.9

76 James Bacchus, An Unnecessary Proposal: A WTO Waiver of Intellectual Property Rights for COVID-19

Vaccines, CATO INSTITUTE, (Dec. 16 2020), https://www.cato.org/publications/free-

tradebulletin/unnecessary-proposal-wto-waiver-intellectual-property-rights-covid.

77 Mercurio, (n.64).
} 
since 1990 but has only been commercialised in $2020 .{ }^{78}$ It is argued that in the absence of financial gain by the IPR owners, the level of $R \& D$ into such products, which have been vital in dealing with Covid-19 pandemic, would have been significantly reduced and innovation would have been hampered and delayed. ${ }^{79}$ While this argument is valid and a correct restatement of the very 'raison d'etre' of IPRs, it misses the point that the proposed waiver is an interim measure to deal with an unprecedented global pandemic. By waiving the applicability of certain IPR rights for a year or so would not permanently disturb the IP system and its role in international trade.

In response to the sponsor's argument that the waiver seeks to facilitate access to low cost vaccine, it is argued that the pharmaceutical companies are already offering the vaccine at very low prices and as such it is doubtful that generic suppliers will provide the vaccine at significantly lower prices. ${ }^{80}$ It is thus feared that the waiver would not necessarily benefit countries in need but rather, it will only benefit generic suppliers who would not need to pay the licence fee to IPR owners. ${ }^{81}$ However, the reality is that the underlying issue is availability of the vaccine to the developing countries not necessarily the price. Evidence on the ground shows that developing countries are willing to buy the vaccine but there isn't enough vaccine being manufactured. Hence the need to bring on board generic suppliers who would increase production capacity and ensure that there is enough vaccine for developing countries to buy. As such the waiver is needed not necessarily for purposes of affordability but rather availability of the vaccine.

The proposed waiver is ideal in so far as dealing with the current COVID-19 situation is concerned. Firstly, the proposed terms of the waiver extend to areas within TRIPS that have become relevant in the wake of the COVID-19 pandemic including copyright and industrial designs. Secondly, the waiver is proposed to be an interim measure that will be in place only until global herd immunity is achieved, and it will be reviewed from time to time. The short-term span of the of proposed waiver should allay the fears of those countries who are of the view that the waiver would be counter-productive and would undermine the existing mechanisms for equitable access of pharmaceutical products within TRIPS. As stated above, the limitations of TRIPS flexibilities are well documented and the unpopularity of the compulsory licensing system in its current form among WTO members is evidence enough that the WTO IP regime is in need of urgent reform. The only problem with the proposed waiver is the mixed reaction it has received among WTO members. There is therefore doubt if it will be backed by a three-fourths majority of the WTO members as required under article IX (2) of the Agreement Establishing the WTO (the Marrakesh Agreement) in order to be adopted.

\subsection{Establishment of Mandatory Patent Pools (Licensing Facilities) and Regional Pharmaceutical Supply Centres (RPSCs).}

\footnotetext{
78 Ibid.

79 Ibid.

$80 \mathrm{lbid}$

81 Ibid.
} 
Abbott and Reichman in their recent paper ${ }^{82}$ have proposed the establishment of Mandatory Patent Pools (Licensing Facilities) and Regional Pharmaceutical Supply Centres (RPSCs) as a solution to the limitations of the voluntary licensing system under TRIPS. It is believed that such arrangements would help to maximize the supply of COVID-19 vaccines, treatments, diagnostics, and medical equipment by allowing open access to the underlying technologies and at the same time would ensure that patent owners are 'compensated by measures that recognize their contributions to the public interest, but not necessarily through elevated sales prices'. ${ }^{83}$ Such facilities would be modelled on other existing voluntary pooling arrangements such as the WHO's voluntary COVID-19 Technology Access Pool ${ }^{84}$ and the voluntary Medicines Patent Pool (MPP), which has also been expanded to cover OVID-19. ${ }^{85}$ However, the proposed Licensing Facilities would differ from the model for these arrangements in that patent owners would be required to contribute their patents under mandatory participation rules.

With regards to mandatory patent pools, it is proposed that governments should agree that owners of patents must place their patents into a 'pool' from which licenses may be freely taken and used by manufacturing companies in return for specified compensation ${ }^{86}$. Further, any restrictions caused by regulatory marketing exclusivity should be waived and compensated by means of the relevant public interest license. However, national, or regional regulatory approvals as required for marketing of generic products would remain but should be facilitated by mutual recognition of approval of bioequivalence ${ }^{87}$. This means that, once a product under license has demonstrated bioequivalence to a recognized stringent regulatory authority, it should be made available for wider distribution as part of the pool mechanism. This would ensure that actual production remains dependent on demonstrating compliance with good manufacturing practice.

It is proposed that the Licensing Facilities should be constituted by government parties through some form of international agreement. They can be established by countries party to existing regional agreements, or simply by groups of like-minded countries, although, a country would not need to become a party to the Licensing Facility in order to take advantage of imports from countries that are parties to it, as long as certain legal steps are taken to comply with international treaties ${ }^{88}$. Patent

\footnotetext{
${ }^{82}$ Frederick M. Abbott and Jerome H. Reichman 'Facilitating Access to Cross-Border Supplies of Patented Pharmaceuticals: The Case of the COVID-19 Pandemic', 2020, (23) Journal of International Economic Law, 535561

83 Ibid. p. 543

${ }^{84}$ WHO COVID-19 technology access pool, <https://www.who.int/emergencies/diseases/novelcoronavirus2019/global-research-on-novel-coronavirus-2019-ncov/covid-19-technology-access-pool> accessed on 09 February 2020.

${ }^{85}$ The Medicines Patent Pool and UNITAID respond to access efforts for COVID-19treatments and technologies', Joint Statement of March 31, 2020

${ }^{86}$ Abbott and Reichman, (n. 71) p. 543

${ }^{87}$ Ibid, p.544.

$88 \mathrm{lbid}$.
} 
owners will be compensated for use of their technology through the payment of royalties and by other means of remuneration. Royalty entitlements of each government entity that is part of the facility may be based on the expenditures within that country for R\&D on the products used to address COVID-19 and any government subsidies to R\&D could be reflected in the computation of royalties so that countries that had more heavily subsidized R\&D would also be entitled to higher aggregate distributions. ${ }^{89}$ Also, any private sector investments would be taken into account.

As an alternative to an internationally agreed Licensing Facility, which may not be easy to achieve in a short time span, Abbot and Reichman suggest that individual governments, like the USA, should consider establishing their own COVID-19 licensing pool using their own licensing policies ${ }^{90}$.

With regard to pooled procurement strategies, it is proposed that developing countries should establish Regional Pharmaceutical Supply Centres (RPSCs), which would help them to strengthen their respective bargaining positions with respect to both patent owners and generic suppliers. ${ }^{91}$ It is also believed that a pooled procurement strategy could catalyse more local production of pharmaceuticals in developing countries partly because potential investors would be offered more advantageous revenue prospects than those offered to importers alone. ${ }^{92}$ Further, such a strategy would strengthen the inherent power of governments in developing countries, which would enable them to issue compulsory licenses for patented pharmaceuticals under Articles 31 and 31 bis of TRIPS. ${ }^{93}$

The proposed RPSCs would be responsible for the implementation of the pooled procurement strategies of different participating governments over time and would assist government agencies in organizing and completing the relevant administrative actions and practical arrangements required under TRIPS. ${ }^{94}$ Further, the RPSCs could assist LDCs in profiting from provisions of Article 31 bis intended to reduce the quantity of licenses needed to be issued when operating within certain regional arrangements. ${ }^{95} \mathrm{It}$ is hoped that a systematically organized strategy for pooled procurements of needed drugs in a number of different countries could stimulate greater interest in generic producers wherever situated as RPSCs would be empowered to implement a number of compulsory licenses, if and when needed. ${ }^{96}$

\footnotetext{
89 Ibid. p. 545

90 Ibid. 547.

${ }^{91}$ Frederick M. Abbott and Jerome H. Reichman, 'The Doha Round's Public Health Legacy: Strategies for the Production and Diffusion of Patented Medicines under the Amended TRIPS Provisions', 10 Journal of International Economic Law 921 (2007).

92 Abbott and Reichman, 2020 (n.71) p. 551

93 Ibid.

94 Ibid. p. 553.

95 Ibid. p. 554

${ }^{96}$ Ibid.
} 
Pooled licencing facilities and pooled procurement strategies as proposed by Abbott and Reichman offers a good alternative to a further amendment of TRIPS or a waiver for the simple reason that any negotiations involving WTO members is bound to take an inordinately long period of time. Although the proposed licensing facilities and RPSCs may also require inter-governmental negotiations and agreements, such negotiations are likely to be less protracted because the negotiating parties will be like-minded and on the same side of the supply-demand divide. For instance, on the supply side, negotiations for the licensing facilities would involve governments that have production capacity and are keen to get a good deal for manufacturers or patent owners within their jurisdiction. Similarly, on the demand side, participating governments would be keen to come up with an agreement that would help them to have easy access to generic medicine to protect their populations.

However, with regards to dealing with COVID-19 pandemic, which is already here and therefore requires immediate action, seeking to come up with new stand-alone inter-governmental agreements to create the proposed licensing facilities or the RPSCs may be a bit far-fetched. A good compromise would be for WTO members to use already existing political and economic groupings that they belong to as vehicles for such arrangements. Examples of such groupings include APEC (Asia-Pacific Economic), ASEAN (Association of South East Asian Nations), AU (African Union) BRICS (Brazil, Russia, India, China and South Africa), CARICOM (Caribbean Community), EU (European Union), G7 (Group of Seven), LATAM (Latin America), MENA (Middle East and North Africa), NAFTA (North American Free Trade Agreement) and OECD (Organisation for Economic Co-operation and Development). These groupings put together countries of sufficiently similar economic and political characteristics and in some cases, geographical positioning. As such they can be used both on the supply side to create the proposed Licensing Facilities as well as the demand side to create RPSCs.

A good example in this regard would be the African Union (AU), which has already started coordinating the process of pooled procurement of COVID-19 vaccine for the African continent. In 2020, the AU established the African Vaccination Acquisition Task Team (AVATT) with a mandate to acquire enough vaccine for the continent to achieve herd immunity by $2022 .{ }^{97}$ It is reported that through AVATT, the AU has so far acquired 1 billion doses of vaccine from the COVAX Facility as well as directly from Pfizer, AstraZeneca, and Johnson \& Johnson. ${ }^{98}$ The acquired vaccines will be allocated on the continental platform set up in 2020, in order to make it easier for all 54 African countries to pool their purchasing power and purchase in bulk. ${ }^{99}$ Although it appears that there is no formal agreement amongst AU members, the current arrangement seeks to achieve the same purpose as the proposed RPSCs. However,

\footnotetext{
${ }^{97}$ See, Khanyi Mlaba, 'Africa Just Secured 1 Billion COVID-19 Vaccine Doses' Global Citizen, 3 February 2021.

98 Ibid.

${ }^{99} \mathrm{lbid}$. Quoting Dr. Nicaise Ndembi, senior science adviser for the Africa Centres for Disease Control and Prevention (Africa CDC)
} 
such an agreement would make a difference as it would make the pooled procurement strategy mandatory and also a bit more coordinated. The current AU arrangement is voluntary and other countries are making their own procurement arrangements directly with vaccine manufacturers. For instance, the government of Seychelles have procured its own vaccination from the Chinese manufacturer, Sinopharm through its subsidiary, the China National Biotec Group. ${ }^{100}$

\section{CONCLUSION}

The above discussion presents a very strong case for a further review of TRIPS. There is still need for revisiting the provisions of Articles 31 and 31 bis of TRIPS in order to streamline the voluntary licensing system, which has clearly not lived up to its expectation. However, facilitating access to COVID-19 vaccines, therapeutics and diagnostics, will require an urgent solution around the current limitations of TRIPS. The proposal by South Africa and India to suspend some of the provisions of TRIPS, though radical, is the most effective and practical. However, in so far as it requires consensus of two-thirds of the WTO members, there is no guarantee that the proposal will be endorsed. On the other hand, the proposal by Abbott and Reichman, on the establishment of pooled licensing facilities and procurement strategies, is a viable and reasonable short to medium term solution.

Due to the urgency with which COVID-19 needs to be dealt with, this paper proposes that WTO members should use already existing political and economic groupings that they belong to as vehicles for such arrangements. This would ensure that these arrangements are implemented within a short period of time. There is already evidence that some regional blocks have already put in place similar arrangements. 